\title{
Pancreas Preservation for Pancreas and Islet Transplantation: A Minireview
}

\author{
J.-P. Squifflet, H. LeDinh, A. de Roover, and M. Meurisse
}

\begin{abstract}
Pancreas preservation by cold storage using University of Wisconsin solution was the mainstay method used for pancreas transplantation during the past 2 decades. Other solutions, such as HTK, Celsior, and SCOT 15, could not demonstrate any advantage for short preservation periods. But the advent of clinical islet transplantation and the larger use of controlled non-heart-beating donors have prompted the transplantation community to develop methods for increasing pancreas graft quality while preventing ischemic reperfusion damages. Oxygenation by 1- or 2-layer methods during pancreas preservation, as well as the use of perfluorocarbons, might increase the islet yield. Based on the former methods, there is a renewed interest in machine perfusion and oxygenation in pancreas preservation for pancreas transplantation and islet preparation.
\end{abstract}

$\mathbf{O}$ utcome after whole organ pancreas transplantation has consistently improved over the past 20 years; islet transplant results are also improving steadily. ${ }^{1}$ The reasons are multifactorial, including improved immunosuppression, ${ }^{2}$ prophylaxis against infections and thrombosis, ${ }^{3}$ and modifications in surgical ${ }^{4}$ and islet preparation techniques. ${ }^{5}$ In addition, improvements in organ preservation have undoubtedly had a significant impact on outcome. ${ }^{5,6}$ That has been achieved by cooling the pancreas organ down to $4-8^{\circ} \mathrm{C}$ and maintaining a milieu of reduced metabolism at low temperatures. But the pancreas has certain unique anatomic aspects. First, when procured for a whole-organ transplant, the pancreas is taken with a segment of duodenum. The bowel (duodenum) is more prone to cold ischemic injury than other abdominal organs. Second, the pancreas is a low-flow organ, as compared with the kidney, so it is more susceptible to barotraumas from aggressive cold perfusion after the aorta is cross-clamped. Therefore, preservation tools and methods for whole-organ pancreas transplantation are not valid for islet transplant preparations. Indeed, cold storage may be adequate for preservation before pancreas transplants, but insufficient when pancreases are processed for islets or when expanded-criteria donors are used. Supplementation of cold storage solutions with cytoprotective agents and machine perfusion may improve pancreas and islet transplant outcomes in the future. ${ }^{7}$

\section{PANCREAS PRESERVATION FOR TRANSPLANTATION}

The 2 main methods used for experimental and clinical pancreas (organ) preservation are static cold storage and machine perfusion. ${ }^{7}$ The hypothermic pulsatile machine perfusion technique, originally developed by Carrel and lately popularized by Belzer, ${ }^{8}$ has been widely used for clinical kidney transplants but not for clinical pancreas preservation.

Early experiments with canine segmental grafts, reported by Florack et $\mathrm{al},{ }^{9}$ demonstrated that failure rates with machine perfusion were $30 \%$ at 24 hours and $40 \%$ at 48 hours. There were no failures at 24 and 48 hours with cold storage. These results, along with the complexities associated with machine perfusion of the pancreas, have made cold storage the preferred and most widely used method for pancreas preservation. ${ }^{7}$

For cold storage of pancreas transplants, the first solutions used were Collins, ${ }^{10,11}$ Sacks, ${ }^{12}$ and Euro-Collins. ${ }^{13}$ But University of Wisconsin solution (UW) ${ }^{14,15}$ became and has been the standard preservation solution for pancreas transplantation for almost 20 years. ${ }^{7}$ Recently, multiple reports have suggested that other preservation solutions may be effective alternatives to UW (Table 1).

Studies comparing histidine-tryptophan-ketoglutarate (HTK) solution with UW have demonstrated similarities between both solutions in the context of low-to-moderate flush volume and short cold ischemia time $(\leq 10 \mathrm{~h})$ for HTK. ${ }^{16-19}$ In contrast, other studies in pancreata flushed

From the Department of Abdominal Surgery and Transplantation, University of Liège, Liège, Belgium.

Address reprints request to Professor Jean-Paul Squifflet, MD, PhD, CHU Sart Tilman, B 35, 4000 Liège, Belgium. E-mail: jean-paul.squifflet@chir-transplantation.be

(C) 2011 by Elsevier Inc. All rights reserved.
360 Park Avenue South, New York, NY 10010-1710 
Table 1. Preservation Solutions

\begin{tabular}{lccccc}
\hline Component (mmol/L) & EC & UW & HTK & Celsior & SCOT 15 \\
\hline $\mathrm{Na}+$ & 10 & 28 & 15 & 100 & 143 \\
$\mathrm{~K}+$ & 113.4 & 125 & 18 & 15 & 5 \\
$\mathrm{Ca}++$ & & & 0.015 & 0.26 & 1.7 \\
$\mathrm{PO}_{4}$ & 57.6 & 25 & 9 & & \\
$\mathrm{HCO}_{3}$ & 10 & & & & 25 \\
Glucose $_{\text {Raffinose }}^{194}$ & & & & 11 \\
Lactobionate & & 100 & & 80 & \\
Gluthation & & 3 & & 3 & \\
Allopurinol & & 1 & & & \\
HES & & $50 \mathrm{~g} / \mathrm{L}$ & & \\
PEG 20 & 1.18 & 3.156 & & 1.15 & 1.05 \\
Viscosity & &
\end{tabular}

Abbreviations: EC, EuroCollins; UW, University of Wisconsin; HTK, histidinetryptophane-ketoglutarate; SCOT, Solution de Conservation d'Organes et de Tissus.

with HTK found a higher incidence of postoperative complications, including graft pancreatitis, use of octreotide, and a decreased rate of insulin independence at hospital discharge. ${ }^{20-22}$

Celsior, an extracellular, low-viscosity preservation solution originally designed for heart transplantation, has also been used for experimental pancreas preservation with controversial results: effective alternative to UW according to Baldan et $\mathrm{al}^{23}$ versus increased ischemia-reperfusion injury according to Uhlmann et al. ${ }^{24}$ For other organs, such as lung ${ }^{25}$ and liver, ${ }^{26-28}$ Celsior solution gave similar clinical results. The first prospective randomized study comparing UW and Celsior for clinical pancreas transplants was reported by Boggi et $\mathrm{al}^{29}$ demonstrating similar safety profiles for pancreas preservation. That was also reported by Manrique et $\mathrm{al}^{30}$ : 2-year graft survival rates, pancreas leakage rates, and clinical graft pancreatitis rates were similar using either solution. That is also true for kidney preservation. $^{31}$

A new preservation solution, SCOT 15 (Solution de Conservation d'Organes et de Tissus), which contains an extracellular ionic composition including polyethylene glycol (PEG) as a colloid, was recently used by Hauet et al, ${ }^{32}$ for experimental organ preservation, but clinical data for pancreas preservation are still lacking.

\section{PANCREAS PRESERVATION FOR ISLET TRANSPLANTATION}

UW has also been used since the 1980s as the pancreas preservation solution for clinical islet transplants. ${ }^{33}$ After other preservation solutions became available, Salehi et $\mathrm{al}^{34}$ reported that islet yields from human pancreases preserved in HTK or UW were equivalent. Another study by Hubert et $\mathrm{al}^{35}$ demonstrated that the islet isolation yields from pancreata preserved with Celsior were 2.1-fold lower than those obtained with UW. That study suggests that colloidfree preservation solutions might be suboptimal for pan- creas perfusion and cold storage before islet isolation and transplantation.

In contrast, Giraud et $\mathrm{al}^{36}$ demonstrated the possibility of clinical application and advantages of using SCOT, which could increase islet yield and reduce graft immunogenicity in pancreatic islet transplantation. Using SCOT, the same authors eventually improved the islet isolation process from pancreata of non-heart-beating donors ${ }^{37}$ in a murine model.

Based on that early experience, there is a consensus among the major islet transplantation centers that islet yields and quality can be improved with better pancreas procurement techniques and by the use of cold-preservation techniques that are not necessarily needed for whole-pancreas transplants. ${ }^{7}$ The 2-layer method (TLM) for pancreas preservation is an example of a technique for improving islet yield and quality by increasing pancreas oxygenation during preservation. Based on several studies, ${ }^{38-40}$ TLM has been widely used by islet transplant centers worldwide, but the mechanisms by which it improves human islet yield and quality are not yet fully understood. It has been suggested by Matsuda et $\mathrm{al}^{41}$ that TLM cold storage protects isolated islets against apoptosis through the mitochondrial pathway. Noguchi et $\mathrm{al}^{42}$ with a pig model, reported that the islet yield from pancreata preserved with TLM and a modified so-called classic solution was significantly higher than with TLM using UW. They hypothesized that their own solution is less likely to inhibit collagenase activity than UW. ${ }^{43}$ Therefore, TLM could be a promising technique for both pancreas and islet transplantation ${ }^{44}$ while using other preservation methods.

The basic principle of TLM is the use of a cold storage solution, mainly UW, in combination with an oxygen carrier solution, the perfluorocarbons (PFC), which have a higher specific gravity. Therefore the PFC solution settles at the bottom and the UW is above it. The pancreas is suspended at the interface of the 2 solutions (Fig 1). Oxygenation of the PFC for 40 minutes before pancreas placement is sufficient to maintain adequate $\mathrm{O}_{2}$ concentrations for up to 24 hours. The oxygenation must be done with a gaseous pressure of $10-12 \mathrm{~mm} \mathrm{Hg}$ and a flow rate of $50-100$ $\mathrm{mL} / \mathrm{min}$. After that period, pancreata can be transported without the oxygenating apparatus. Moreover, it has been shown that maintaining the temperature of the medium at $8^{\circ} \mathrm{C}$ rather than $4^{\circ} \mathrm{C}$ results in superior islet function. ${ }^{6}$ The beneficial role of oxygenation for improving pancreas quality and islet isolation was also experimentally demonstrated by Hackl et $\mathrm{al}^{45}$ using simple preoxygenation of different preservation solutions (UW, HTK, Celsior) and by Scott et al using persufflation. ${ }^{46}$

Therefore, using the 1- and two-layer methods, using perfluorocarbons, which are inert solutions with a high capacity for dissolving oxygen, or oxygenation with other tools, these methods have been proving to be successful for pancreas preservation by cold storage. Taking into account that PFCs can be formulated as an emulsion, there is a huge renewal of interest in using the emulsion for continual 


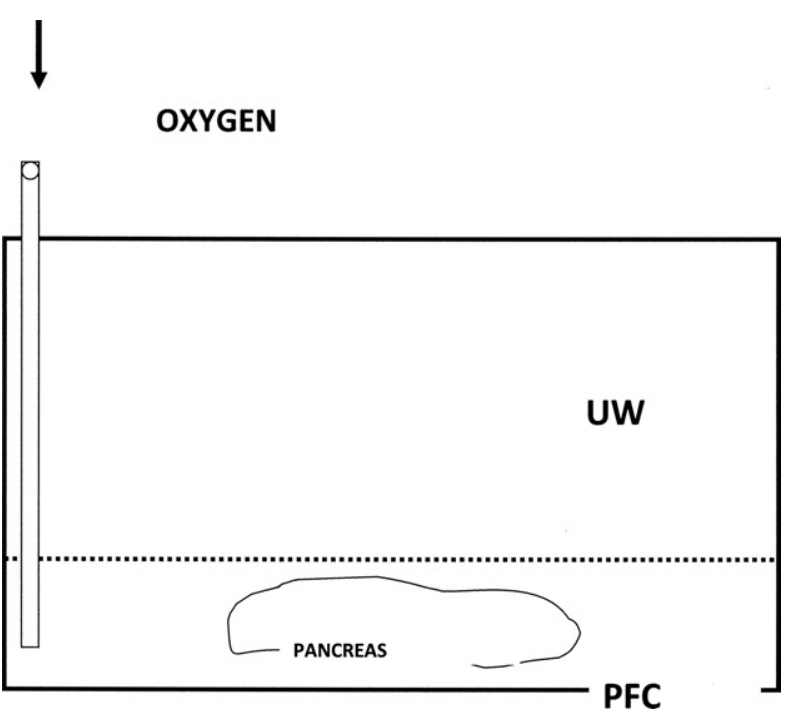

Fig 1. The 2-layer method: University of Wisconsin (UW) solution is above and perfluorocarbons (PFC) solution below.

machine perfusion or as simple flush solution. ${ }^{47}$ Indeed, Taylor et $\mathrm{al}^{48}$ reported that islet isolation from juvenile porcine pancreas after 24-hour hypothermic machine perfusion (HMP) preservation can be successfully achieved; HMP is well tolerated, leading to moderate edema but no loss of function of the harvested islets. Moreover, the edema appears to aid in enzymatic digestion, producing a greater yield and purity of islets compared with pancreas subjected to 24 hours of static cold storage. In parallel, Karcz et $\mathrm{al}^{49}$ have developed a model of machine perfusion for porcine pancreata that is simple, reliable, and protects graft histopathologic integrity. The model can be used in further studies to improve the quality of pancreas preservation and to assess the condition of and improve the viability of borderline pancreatic grafts.

\section{CONCLUSION}

With the number of pancreas transplants increasing and the advent of clinical islet transplants, a significant shortage of pancreata will appear soon. Better preservation methods than just cold storage of donor pancreata will be needed. Because controlled non-heart-beating donors (NHBDs) may be a potential source for pancreata, other preservation methods might be foreseen. Indeed, with NHBDs, significant ischemic damage and postoperative complications might especially occur with prolonged preservation using cold storage. ${ }^{50,51}$ The use of TLM has shown promise in prolonging clinical pancreas preservation times and ameliorating warm ischemic insult. ${ }^{6}$

Therefore, there is an urgent need to get access to the TLM technology not only for pancreas preservation for islet transplantation, but also for pancreas transplantation. The machine perfusion technique is also a pancreas preservation method that needs to be reevaluated in the light of new technologies using other perfusion fluids, temperatures, and oxygenation for conditioning the pancreatic graft.

\section{REFERENCES}

1. Robertson RP, Nathan DM, Muylder JE: Pancreas and islet transplantation in diabetes mellitus. Available at: http://www. uptodate.com (version 18.3: September 2010)

2. Malaise J, DeRoover A, Squifflet JP, Land W: Immunosuppression in pancreas transplantation. Acta Chir Belg 108:673, 2008

3. Muthusamy ASR, Giangrande PLF, Friend PJ: Pancreas allograft thrombosis. Transplantation 90:705, 2010

4. Squifflet JP, Gruessner R, Sutherland DER: The history of pancreas transplantation: past, present and future. Acta Chir Belg 108:367, 2008

5. Baertschiger RM, Berney T, Morel P. Organ preservation in pancreas and islet transplantation. Curr Opin Organ Transplant 13:59, 2008

6. Kandaswamy R: Pancreas preservation. In Gruessner RWG, Sutherland DER: Transplantation of the Pancreas. New York: Springer-Verlag; 2004: p 119

7. Iwanaga Y, Sutherland DER, Harmon JV, Papas KK: Pancreas preservation for pancreas and islet transplantation. Curr Opin Organ Transplant 13:445, 2008

8. Belzer FO, Ashby BS, Dunphy JE: 24-hour and 72-hour preservation of canine kidneys. Lancet 2:536, 1967

9. Florack G, Sutherland DER, Heil J, et al: Preservation of canine segmental pancreatic autografts: cold storage versus pulsatile machine perfusion. J Surg Res 34:493, 1983

10. Collins GM, Bravo-Shugarman M, Terasaki PI: Kidney preservation for transplantation. Initial perfusion and 30 hours' ice storage. Lancet 2:1219, 1969

11. Hardie I, Balderson G, Hamlyn L, et al: Extended ice storage of canine kidneys using hyperosmolar Collins solution. Transplantation 23:282, 1977

12. Sacks SA, Petritsch PH, Kaufman JJ. Canine kidney preservation using a new perfusate. Lancet 1:1024, 1973

13. Dreikorn K, Horsch R, Rohl L. 48- to 96-hour preservation of canine kidneys by initial perfusion and hypothermic storage using the Euro-Collins solution. Eur Urol 6:221, 1980

14. Walhlberg JA, R. Love R, Landegaard L, et al: 72-hour preservation of the canine pancreas. Transplantation 43:5, 1987

15. Wahlberg JA, Southard JH, Belzer FO: Development of a cold storage solution for pancreas preservation. Cryobiology 23: 477, 1986

16. Englesbe MJ, Moyer A, Kim DY, et al: Early pancreas transplant outcomes with histidine-tryptophan-ketoglutarate preservation: a multicenter study. Transplantation 82:136, 2006

17. Becker T, Ringe T, Nyibata M, et al: Pancreas transplantation with histidine-tryptophan-ketoglutarate (HTK) solution and University of Wisconsin (UW) solution: is there a difference? JOP 8:304, 2007

18. Schneeberger S, Bielb M, Steurer W, et al: A prospective randomized multicenter trial comparing histidine-tryptophanketoglutarate versus University Wisconsin perfusion solution in clinical pancreas transplantation. Transplant Int 22:217, 2009

19. Fridell JA, Mangus RS, Powelson JA: Histidine-tryptophanketoglutarate for pancreas allograft preservation: the Indiana University experience. Am J Transplant 10:1284, 2010

20. Alonso D, Dunn TB, Rigley T, et al: Increased pancreatitis in allografts flushed with histidine-tryptophan-ketoglutarate solution: a cautionary tale. Am J Transplant 8:1942, 2008

21. Stewart ZA, Cameron AM, Singer AL, et al: Histidinetryptophan-ketoglutarate (HTK) is associated with reduced graft survival in pancreas transplantation. Am J Transplant 9:217, 2009

22. Stewart ZA, Lonze BE, Warren DS, et al: Histidinetryptophan-ketoglutarate (HTK) is associated with reduced graft survival of deceased donor kidney transplants. Am J Transplant 9:1048, 2009 
23. Baldan N, Rigotti P, Furian L, et al: Pancreas preservation with Celsior solution in a pig autotransplantation model: comparative study with University of Wisconsin solution. Transplant Proc 33:873, 2001

24. Uhlmann D, Armann B, Ludwig S, et al: Comparison of Celsior and UW solution in experimental pancreas preservation. J Surg Res 105:173, 2002

25. Thabut G, Vinatier I, Brugiere $\mathrm{O}$, et al: Influence of preservation solution on early graft failure in clinical lung transplantation. Am J Crit Care Med 164:1204, 2001

26. Maggi U, Caccamo L, Gatti S, et al: Celsior solution and clinical liver transplantation. Transplant Proc 32:36, 2000

27. Lama C, Rafecas A, Figueras J, et al: Comparative study of Celsior and Belzer solutions for hepatic graft preservation: preliminary results. Transplant Proc 34:54, 2002

28. Cavallari A, Cillo U, Nardo B, et al. A multicenter pilot prospective study comparing Celsior and University of Wisconsin preserving solutions for use in liver transplantation. Liver Transpl 9:814, 2003

29. Boggi U, Vistoli F, del Chiaro M, et al: Pancreas preservation with University of Wisconsin and Celsior solutions: a singlecenter, prospective, randomized pilot study. Transplantation 77: 1186, 2004

30. Maurique A, Jimenez C, Herrero ML, et al: Pancreas preservation with the University of Wisconsin versus Celsior solutions. Transplant Proc 38:2582, 2006

31. Faenza A, Catena F, Nardo B, et al: Kidney preservation with University of Wisconsin and Celsior solution: a prospective multicenter randomized study. Transplantation 72:1274, 2001

32. Hauet T, Eugene M: A new approach in organ preservation: potential role of new polymers. Kidney Int 74:998, 2008

33. Zuker PF, Bloom AD, Strasser S, Alejandro R: Successful cold storage preservation of canine pancreas with UW-1 solution prior to islet isolation. Transplantation 48:148, 1989

34. Salehi P, Hansen MA, Avila JG, et al: Human islet isolation outcomes from pancreata preserved with histidine-tryptophanketoglutarate versus University of Wisconsin solution. Transplantation 82:983, 2006

35. Hubert T, Gmyr V, Arnalsteen L, et al: Influence of preservation solution on human islet isolation outcome. Transplantation 83:270, 2007

36. Giraud S, Claire B, Eugene M, et al: A new preservation solution increased islet yield and reduces graft immunogenicity in pancreatic islet transplantation. Transplantation 83:1397, 2007

37. Giraud S, Hauet T, Eugene M, et al: A new preservation solution (SCOT 15) improves the islet isolation process from pancreata of non-heart-beating donors: a murine model. Transplant Proc 41:3293, 2009

38. Hering BJ, Matsumoto I, Sawada $\mathrm{T}$, et al: Impact of two-layer pancreas preservation on islet isolation and transplantation. Transplantation 74:1813, 2002

39. Fraker CA, Alejandro R, Ricordi C: Use of oxygenated perfluorocarbon toward making every pancreas count. Transplantation 74:1811, 2002

40. Lakey JR, Tsujimura T, Shapiro AM, Kuroda Y: Preservation of the human pancreas before islet isolation using a two-layer (UW solution-perfluorochemical) cold storage method. Transplantation 74:1809, 2002

41. Matsuda T, Suzuki Y, Tanioka Y, et al: Pancreas preservation by the 2-layer cold storage method before islet isolation protects isolated islets against apoptosis through the mitochondrial pathway. Surgery 134:437, 2003

42. Noguchi H, Naziruddin B, Onaca N, et al: Comparison of modified Celsior solution and M-Kyoto solution for pancreas preservation in human islet isolation. Cell Transplant 19:751, 2010

43. Contractor HH, Johnson PR, Chadwick DR, et al: The effect of UW solution and its components on the collagenase digestion of human and porcine pancreas. Cell Transplant 4:615, 1995

44. Fujino Y: Two-layer cold storage method for pancreas and islet transplantation. World J Gastroenterol 16:3235, 2010

45. Hackl F, Stiegler P, Stadlbaner V, et al: Preoxygenation of different preservation solutions for porcine pancreas preservation. Transplant Proc 42:1621, 2010

46. Scott WE, O'Brien TD, Ferrer-Fabrega J, et al: Persufflation improves pancreas preservation when compared with the two-layer method. Transplant Proc 42:2016, 2010

47. Hosgood SA, Nicholson ML: The role of perfluorocarbon in organ preservation. Transplantation 89:1169, 2010

48. Taylor MJ, Baicu S, Greene E, et al: Islet isolation from juvenile porcine pancreas after 24-h hypothermic machine perfusion preservation. Cell Transplant 19:613, 2010

49. Karcz M, Cook HT, Sibbons P, et al: An ex-vivo model for hypothermic pulsatile perfusion of porcine pancreas: hemodynamic and morphologic characteristics. Exp Clin Transplant 8:55, 2010

50. d'Alessandro AM, Hoffman RM, Knechtle SJ, et al: Controlled non-heart-beating donors: a potential source of extrarenal organs. Transplant Proc 27:707, 1995

51. Humar A, Kandaswamy R, Drangstveit MB, et al: Prolonged preservation increases surgical complications after pancreas transplants. Surgery 127:545, 2000 